\title{
The Psychologist's Role in Assessing and Facilitating Patients' Knowledge of Advance Directives in Medical Settings: A Preliminary Investigation
}

\author{
Doug Johnson-Greene, ${ }^{1,2}$ Cheryl M. Anderson, ${ }^{2}$ Kenneth M. Adams, ${ }^{1-3}$ \\ Henry A. Buchtel, ${ }^{1,2}$ Todd Miller, ${ }^{2}$ and Michael Dehring ${ }^{2}$
}

In a time of budgetary shortfalls in the medical industry, an aging population, and an increased emphasis on health care choices, psychologists are being called upon to administer advance medical directive programs to patients. This study reports preliminary findings from a program to assess and facilitate patients' knowledge of advance directives (ADs) by the Psychology Service at the Ann Arbor VA Medical Center. The participant pool included 243 male veteran patients admitted to medical and surgical wards at the hospital. The intervention included the use of a computer-generated prompt for consultation, which was sent to the psychology staff in response to a patient inquiry regarding ADs. It also involved an increased emphasis on the delivery of written material on $A D s$ by the admissions clerks. The intervention appeared to result in a modest increase in patients' knowledge of advance directives. Suggestions are offered for areas that should be emphasized in future attempts to increase patients' knowledge and utilization of advance directives.

KEY WORDS: education; knowledge; illness; health choices.

${ }^{1}$ Department of Psychiatry-Neuropsychology Division, University of Michigan, Ann Arbor, Michigan.

${ }^{2}$ Department of Psychology, Veterans Affairs Medical Center, Ann Arbor, Michigan.

${ }^{3}$ To whom correspondence should be addressed at Psychology Service (116B), VA Medical Center, Ann Arbor, Michigan 48105. 


\section{INTRODUCTION}

In recent years medical advances have dramatically extended the lives of patients. These developments relate not only to improved capacity to survive acute disease or trauma, but to the efficacy of medical therapies in delaying death from chronic or terminal illness. Unfortunately, guidelines pertaining to the ethical implications and impact of these advances have lagged behind their implementation. This has resulted in new dilemmas in medicine as the end of life approaches. These dilemmas are particularly poignant for cases in which patients are sustained in a persistent vegetative state. In most instances of terminal disease, a patient's ability to decide if and when the discontinue life-sustaining measures is compromised. In these situations, family members may be called upon to provide information to facilitate decisions regarding the withholding or withdrawal of life supporting medical interventions.

Guardians for some of these patients have, in the recent past, engaged in long and costly legal battles in an attempt to withdraw life-sustaining medical care. Notably, the Quinlan (1976) and Cruzan (1990) legal cases drew national attention to decision-making processes regarding the withdrawal of life-sustaining treatments from patients in persistent vegetative states. In response to these cases and other developments in American society, Congress enacted the Patient Self-Determination Act (PSDA, 1990).

Starting in 1991, the PSDA required all institutions and programs accepting Medicare and Medicaid to query patients concerning their advance medical directive preferences prior to admission or delivery of care. Completion of an advance directive enables patients to declare formally a binding expression of their treatment preferences regarding life-sustaining treatment or to designate an individual to act on their behalf in the event of their incapacitation. The statute includes a provision that institutions or organizations "provide (individually or with others) for education for staff and the community on issues concerning advanced directives." It should be emphasized that executing and advance directive does not necessarily imply a blanket rejection of life-sustaining treatments; some patients use narrative sections of treatment preferences or other available options to assert their wish for life support under certain conditions.

It has been suggested that there may be a discrepancy between patients' interest in and actual use of advanced medical directives. One study of individuals from the Boston area estimated that advance directives were desired by $93 \%$ of an outpatient sample and by $89 \%$ of the general public (Emmanuel, Barry, Stoeckle, \& Ettelson, 1991). However, recent investigations suggest that only a small percentage of U.S. citizens is actually completing advance directives. High (1993a) reported, in his study of pa- 
tients' familiarity with advance directives, that most individuals were quite knowledgeable about this topic. Nevertheless, recent studies have found that completion of advance directives remains low (Gamble, McDonald, \& Lichstein, 1991; Zweibel \& Cassel, 1989). In an attempt to explain this discrepancy between knowledge and use, current research has attempted to explore the apparent under utilization of advance directives. A subsidiary focus of some of these studies has been to explore various methods of facilitating and improving an institution's adherence to the PSDA guidelines.

Robinson, DeHaven, and Koch (1993) attempted to facilitate PSDA guidelines at participating institutions by giving the patient written information about advance directives upon admission and subsequently questioning the patient about the completion of the advance directive forms. These authors reported that significantly more patients demonstrated familiarity with advance directives following this educational intervention. Results of this study suggest that most patients can obtain an adequate level of knowledge concerning advance directives when provided with written materials.

Although research concerning educational interventions has been able to demonstrate a positive impact on patient knowledge, this increase has had a limited effect upon patient behavior. Robinson et al. (1993) concluded that "broad distribution of information regarding their legal rights to all patients may be essentially a wasted effort and expense." In contrast, Stelter, Elliot, and Bruno (1992) concluded that the experience of hearing presentations had encouraged more individuals to complete advance directives.

Further review of the literature suggests that more personal interactions with patients may be useful in increasing advance directive adoption. Hare and Pratt (1993) examined the impact of two educational approaches: an educational workshop and a home study program.

The educational workshop taught by a family life specialist included reviews of the Cruzan (1990) case and relevant stace laws, directions for completing an advance directive, a 10-min video clip (i.e., A Fate Worse Than Death), which takes the viewer to the bedside of patients in a persistent vegetative state (KGW-TV Portland, 1990), review of life-prolonging treatments, and a discussion about the importance of articulating one's wishes to primary health care providers in advance of a health crisis. The home study program consisted of reading material, activities, worksheets, and discussion questions for home use.

These investigators found that workshop participants were significantly more likely to think about health preferences and share those preferences with others. Following the workshop, patients reported that it was easier to discuss health care decisions with their physicians and complete advance directives. Importantly, Hare and Pratt noted that after attending a workshop, physician 
follow-up may be critical to encourage actual completion of an advance directive. They believed that physicians should initiate conversations about advance directives with all of their patients because of the observation that only highly motivated patients will participate in educational programs.

These findings are consistent with those of High (1993b), who noted that mere educational intervention efforts do not produce increase utilization of advance directives. However, he did suggest that "a moderate amount of carefully drafted and easily understood information together with easily accessible help to execute the necessary forms provides the best hope of significantly increasing use."

Following on the results in the literature to date, the goals of the present investigation were (a) to collect normative information concerning patients' understanding of advance directive-related information, (b) to determine the association between specific patient characteristics and advance directive knowledge, and (c) examine the effect of an intervention program on patients' knowledge of advance directives (ADs).

The psychologists at our medical center are well positioned to carry out these goals because we have been chosen by the hospital management to handle inpatient ADs. Until 1994, this activity was assigned to social workers, who continue to work with outpatients who want to consider ADs. There are several reasons that the management reassigned inpatient $\mathrm{ADs}$ to psychologists. First, many inpatients are ill enough, physically or mentally, that they need an assessment of their competency to make health care decisions before executing an $\mathrm{AD}$, and psychologists can assess competency during the initial interview. Second, inpatients who begin thinking about $\mathrm{ADs}$ are frequently at a critical point in their health care (e.g., just before surgery or just having heard about a terminal condition such as inoperable cancer) and may need a brief intervention as an initial part of their decision process. Third, topics occasionally surface during the interview that point to the need for a more substantial intervention, as in the case of patients who show signs of thought distortions or serious depression and hopelessness about their condition. Since one's attitude toward personal health has a documented effect on medical illnesses and recovery, the interviews with a psychologist can be expected to help with mood and, potentially, with the course of the illness.

\section{METHOD}

\section{Subjects}

The participants in this study consisted of 243 male veteran nonconsecutive inpatient admissions to medical and surgical services at the Ann 
Arbor Veteran's Hospital selected randomly over a 3-month period of time. Patients who had an impaired level of alertness or who had severely impaired cognition $(N=13)$ were excluded from participation in the study. Only 26 of the remaining 230 patients (9\%) had a preexisting advance directive on file at the time of their admission. All patients completed a brief questionnaire that solicited demographic information including age, education level, marital status, and religion. A summary of this information is given in Table $\mathrm{I}$.

Table I. Patient Demographic Information

\begin{tabular}{|c|c|}
\hline Age & \\
\hline Under 35 & 10 \\
\hline $35-45$ & 33 \\
\hline $46-55$ & 35 \\
\hline $56-65$ & 57 \\
\hline 66 or over & 62 \\
\hline \multicolumn{2}{|l|}{ Education } \\
\hline Under 12 years & 77 \\
\hline High school & 96 \\
\hline Over 12 years & 57 \\
\hline \multicolumn{2}{|l|}{ Marital status } \\
\hline Married & 108 \\
\hline Divorced & 75 \\
\hline Widowed & 16 \\
\hline Seperated & 3 \\
\hline Single & 28 \\
\hline \multicolumn{2}{|l|}{ Religion } \\
\hline Catholic & 48 \\
\hline Baptist & 29 \\
\hline Protestant & 61 \\
\hline Lutheran & 25 \\
\hline Jewish & 3 \\
\hline Other & 20 \\
\hline Nondenominational & 44 \\
\hline \multicolumn{2}{|l|}{ Admitting diagnosis } \\
\hline Cardiac/vascular & 79 \\
\hline Orthopedic & 13 \\
\hline Pulmonary & 13 \\
\hline Psych/substance abuse & 17 \\
\hline Infection & 23 \\
\hline Cancer & 28 \\
\hline Gastro/urology & 35 \\
\hline Other & 11 \\
\hline
\end{tabular}

Note. Numbers represent patients in each category. Data on patients' age were available for 197 of the 230 participants sampled. 


\section{Procedure}

All patient completed a multiple-choice test designed to assess their current knowledge of advance directives (see the Appendix for an example of the Advance Directive Survey). The test covered the following domains: general definition, conditions for completion, reversibility, sources of additional information, and optimal time to complete an advance directive. All questionnaires had enlarged typeface (i.e., Times 14-point font) and were consistent with the patient's educational level. For patients with visual or mobility impairments, questions were presented orally and responses were recorded by the researchers. All patients with scheduled admissions received a Patient's Rights Handbook prior to their admission, which contained a brief section describing advance directives in nontechnical language.

The investigation was conducted in two phases as an A-B design: a baseline phase, which consisted of the assessment procedures previously described; and an intervention phase. A total of 56 and 174 patients were sampled during each of the respective phases of the study. The intervention phase relied upon automated computer messages (Buchtel, Anderson, Adams, \& Johnson-Greene, 1995) to prompt hospital admission clerks to emphasize the availability of advance directives for incoming patients. Specifically, at the time of admission, clerks asked patients if they had an advance directive, if it was on file, and if they had questions about, or an interest in, completing an advance directive. The answers to these three questions were entered into the computer by the clerk. If the patient had further questions or wished to complete an $\mathrm{AD}$, an e-mail message was automatically generated and sent to the Advance Directive Team, following which they were seen by a psychologist who was able to provide written material and consultation, usually on the same day as admission. Patients were also given written materials which provided factual information about advance directives by admission clerks upon arrival to the hospital.

\section{RESULTS}

The results suggest that the intervention used in this investigation did produce an overall increase in patients' knowledge of advance directives over baseline as measured by the total number of correct responses on the multiple-choice test, although this increase did not reach statistical significance $(t=-1.59, p<.11)$. As Fig. 1 illustrates, the intervention phase was particularly successful in increasing patients' understanding in two areas: 
General Knowledge or advance directives $(t=3.02, p<.003)$ and Conditions of Completion $(t=2.09, p<.04)$.

Of the 173 patients sampled in the intervention phase, approximately $39 \%(n=67)$ of the total patient sample reported that they had read the material given to them regarding advance directives. Surprisingly, there was no significant difference in the number of correct responses on the multiple-choice quiz for patients who reported that they had obtained and read written material concerning advance directives compared to those who did not read this material $(t=.13, p<.61)$.

Several factors were found to be significantly related to patients' knowledge of advance directives. Consistent with previous studies in this area, subjects who had more years of education demonstrated an increased knowledge of advance directives $(r=.31, p<.001)$. Age was found to be significantly inversely related to knowledge of advance directives $(r=-.26, p<.001)$. Specifically, younger patients had a superior knowledge of advance directives compared to older patients. Also, marital status was significantly related to knowledge of advance directives $\left[\chi^{2}(4, N=228)=10.61, p<.024\right]$. Single patients were more knowledgeable about advance directives than married or divorced patients. In contrast, religious affiliation had no effect upon patients' understanding of advance directives $\left[\chi^{2}(6, N=229)=6.61, p<.32\right]$.

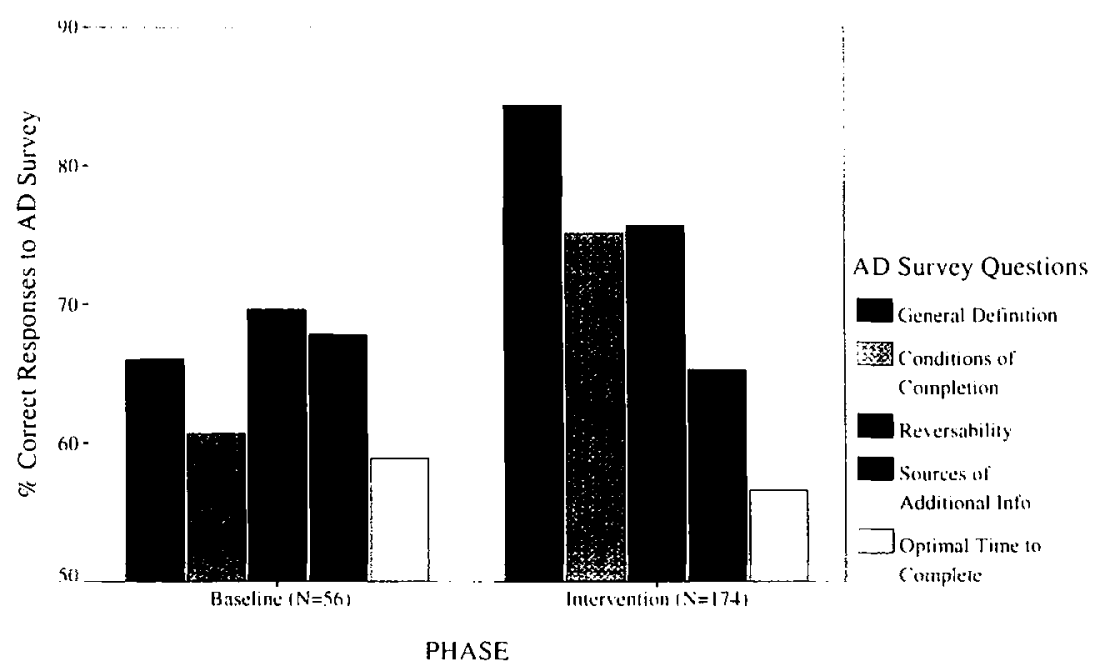

Fig. 1. Patient responses to the Advance Directive Survey. 


\section{DISCUSSION}

Overall, the results of this study suggest that patients' baseline knowledge of advance directives was poor, and even after provision of detailed information their grasp of the material was circumscribed. The primary areas in which patients had a relative lack of understanding of advance directives include the optimal putative time for completion and whom they should ask for additional information concerning advance directives. These findings are particularly distressing in light of patients' tendency to consider advance directives only in the midst of a medical crisis. In such instances, patients are more often incapacitated and less able to make decisions concerning health care options. These results further highlight the need for trained personnel to provide information concerning $\mathrm{AD}$ in a timely manner.

There has been little consensus on how best to implement the mandates of the Patient Self-Determination Act. Practices concerning the dissemination of information and implementation of advance directives vary from one health care facility to the next. Written material has been one option utilized by some hospitals, although the literature has mixed reports concerning its effectiveness. The results of this investigation suggest that this method of information dissemination, in combination with prompting by admission clerks, may be somewhat inadequate in that patient's overall knowledge of advance directives did not statistically increase, although it does appear to increase general knowledge and requirements for completion. In our study, age, education, and marital status were significantly related to patients' knowledge of advance directives. Younger, single, and more educated patients had an increased knowledge of advance directives compared to older, married, and less educated patients. These results may represent a cohort effect to the extent that some older patients may have a tendency to be less actively involved in their own health care.

In addition to providing written materials, it may be advisable for hospitals to adopt an educative approach by providing consultation services specifically targeted at educating patients who have indicated a desire to obtain additional information concerning $\mathrm{AD}$. Our most recent efforts at the Ann Arbor Veterans Hospital suggest that a consultation team, whose goal is to respond to patients' requests for additional information, may have a much stronger effect than simply providing written materials to patients, both in terms of increasing their knowledge and in terms of the number of advance directives completed. This may be due to the incremental effect of individual and personal contact. Although this approach may be more labor intensive, the potential benefits warrant future research in this area. Psychologists may be in a unique position to provide such services given 
their background, training, and familiarity with hospital settings and protocol. For example, psychologists conducting an $\mathrm{AD}$ interview with a patient are particularly sensitive to misconceptions and distortions of thinking. They frequently have to help patients sort out the extent to which their health care decisions are based on financial considerations rather than on their own wishes or what might be the psychological impact of a long predeath coma on the family and friends. For example, some of the patients we have talked to are concerned that if they are not put on life support, an early death will cause financial loss to their family because their pension or Social Security payments will be suspended. Other patients feel pushed into signing an advance directive by family who are anxious to avoid the psychological stresses of seeing a loved one linger on life support in a terminal illness. This requires considerable sensitivity in helping the patient dissociate his or her feelings from those of the family.

In the present study, the limited level of education and lower than average socioeconomic status of this randomly selected veteran sample may have influenced the results of this study. Our experience has suggested that patients confuse terms such as "living wills" and "durable power of attorney" with more general matters of personal will and estate. Such matters can be off-putting and even frightening to patients in general; and the message concerning actual empowerment conferred by advance directives may be lost on the patient.

Another question unanswered in this study concerns the optimal time to measure the impact (if any) of patient education interventions in this area. Studies on outpatient settings indicate no effect of mass dissemination of advance directive information by mail after several months have elapsed. The intervention follow-up interval was much shorter in the present study (1-2 days), but it is also the case that our patients may have had a great deal done to them after admission and could hardly focus on the advance directive issue.

An allied question relates to the emotional effect of discussions about advance directives. Some clinicians are concerned that even routine discussions or presentation of advance directive material may serve to reduce patients' optimism concerning the success of their medical care. These colleagues would prefer that such discussions be held at another time. The problem with this stance, however, is that this may prevent the implementation of the very protection that advance directives were legislated to create. Clearly a pathway is needed to determine an optimal way to balance patient hope and rights protection. More generally, research is needed in the realm of advance directives in the full context of health care delivery and societal need. 


\section{APPENDIX}

\section{Advance Directive Survey}

1. What is an Advance Directive (living will)?

a. A hospital phone book used by patients.

b. A surgical procedure performed at the VA Medical Center.

c. A special parking permit to park in front of the hospital.

d. How I want to be cared for in the hospital if I am unable to tell others.

2. Is an Advance Directive (living will) available here?

a. Yes, it is available at this hospital.

b. Yes, but only when someone is very ill.

c. Yes, but family members must sign also.

d. No, an Advance Directive is not available at this hospital.

3. Can I change an Advance Directive (living will) after I have signed it?

a. Yes, it can be changed at any time.

b. Yes, but a lawyer must be present.

c. Yes, it must be changed each time you enter the hospital.

d. No, it is a lifetime contract.

4. If I have questions about an Advance Directive (living will), I can ask which of the following people?
a. Doctor
b. Nurse
c. Admissions clerk
d. All of the above

5. I should complete an Advance Directive (living will) when?
a. Before "major" surgeries.
b. Only as an outpatient.
c. Anytime I wish to complete one.
d. Only when my doctor tells me to complete one.

\section{ACKNOWLEDGMENTS}

The authors would like to express their appreciation to Jeanne Schneider for her administrative assistance with the advance directive program. We would also like to thank Holly Jo Sparks, Christine Santiago, Joy Rook, and Melanie Topper for their assistance with data collection.

This study was partly supported by NIH Grants AA 00378, NS15655, and AG 08671 and NIAAA Training Grant 2T32AA07477. 


\section{REFERENCES}

Buchtel, H. A., Anderson, C., Adams, K. M., \& Johnson-Greene, D. (1995). Making sure patients are informed about advanced directives in the VA. QA News, 4(2), 6, 16.

Cruzan v. Director, Missouri Department of Health, 497 U.S. 261, 110 S. Ct. 2841(1990).

Emmanuel, L. L., Barry, M. J., Stoeckle, J. D., \& Ettelson, L. M. (1991). Advance directives for medical care: A case for greater use. New England Journal of Medicine, 324, 889-895.

Gamble, E. R., McDonald, P. J., \& Lichstein, P. R. (1991). Knowledge, attitudes, and behavior of elderly persons regarding living wills. Archives of Internal Medicine, 151, 277-280.

Hare, J., \& Pratt, C. (1993). Evaluation of two educational programs for advance health care planning. Health Values, 17, 18-26.

High, D. M. (1988). All in the family: Extended autonomy and expectations in surrogate health care decision making. The Gerontologist, 28, 46-51.

High, D. M. (1993a). Why are elderly people not using directives? Joumal of Aging and Health, $5,497-515$.

High, D. M. (1993b). Directives and the elderly: A study of intervention strategies to increase use. The Gerontologist, 33, 342-349.

Holly, J. L., Nespor, S., \& Rault, R. (1993). The effects of providing chronic hemodialysis patients written material on directives. American Joumal of Kidney Disease, 22(3), 413-418.

In re Quinlin, 70 N.J. 10, 355 A.2d 647 (1976).

KGW-TV Portland (1990). A fate worse than death [film]. Available from Fanlight Productions, Boston.

Patient Self-Determination Act (1990). Pub L. 101-508 4206, 4751 (OBRA), 42 U.S.C. $1395 \mathrm{cc}(\mathrm{a})$ et seq. (1990).

Robinson, M. K., DeHaven, M. J., \& Koch, K. A. (1993). Effects of patient self-determination act on patient knowledge and behavior. The Journal of Family Practice, 37, 363-368.

Stelter, K. L., Elliot, B. A., \& Bruno, C. A. (1992). Living will completion by older adults. Archives of Internal Medicine, 152(5), 954-959.

Zweibel, N. R., \& Cassel, C. K. (1989). Treatment choices at the end of life: A comparison of decisions by older patients and their physician-selected proxies. The Gerontologist, 29, 615-621. 